\title{
Consumo, Dinheiro e Diferenciações Sociais: Ditos de Jovens em uma Pesquisa-Intervenção
}

\author{
Inês Hennigen \\ Universidade Federal do Rio Grande do Sul, \\ Porto Alegre, RS. \\ Bruno Eduardo Procopiuk Walter \\ Universidade Federal do Rio Grande do Sul, \\ Porto Alegre, RS. \\ Guilherme Machado Paim \\ Universidade Federal do Rio Grande do Sul, Porto Alegre, RS.
}

\begin{abstract}
Resumo: Na conjuntura das discussões pós-estruturalistas acerca dos processos de subjetivação, bem como dos trabalhos de autores como Hannah Arendt, Zygmunt Bauman e Jurandir Freire Costa, é indubitável reconhecer o impacto do consumo, entendido enquanto prática social, na constituição dos sujeitos contemporâneos. Em função disso, realizamos uma pesquisa-intervenção objetivando abrir espaços de discussão e experimentações, e esboçar um quadro analítico sobre posicionamentos e vicissitudes na relação jovens/consumo. A pesquisa desenvolveu-se em duas escolas públicas de Porto Alegre com 35 jovens de 14 a 17 anos. A análise do discurso pautada nas contribuições foucaultianas nos guiou na análise do que foi dito nos encontros. No processo de pesquisa emergiram questões como: estratégias dos jovens para obter dinheiro, diferenciação e status social a partir do consumo, e a internet enquanto necessidade de primeira ordem. Dentre outros, analisamos neste artigo o enunciado "consumir é gastar dinheiro", que se torna dizível a partir de mudanças históricas (como a transformação da nossa relação com os objetos de uso), da posição do jovem enquanto dependente econômico de seus pais e responsáveis, entre outros aspectos. Fechamos o artigo argumentando em favor de iniciativas que visem uma educação quanto ao consumo, sustentada em um compromisso ético-político de possibilitar outros agenciamentos em relação a modos de subjetivação correntes. Neste sentido, pensamos ser um desafio para a Psicologia oferecer contribuições por meio da produção de conhecimentos e de práticas, pois se trata de temática que conta com estudos ainda bem pontuais, ao menos no que concerne à juventude.
\end{abstract}

Palavras-chave: Consumo, Juventude, Pesquisa-Intervenção, Produção de Subjetividade, Educação quanto ao consumo. 


\title{
Consumption, Money and Social Differentiation: what Was Said by Youngsters in an Intervention Research
}

\begin{abstract}
In the context of post-structuralism discussions about the processes of subjectivation, as well as the works of authors such as Hannah Arendt, Zygmunt Bauman and Jurandir Freire Costa, there is no doubt of the impact of consumption, understood as social practice, in the constitution of contemporary subjects. Thus, an intervention research was designed aiming to open up spaces for discussion and experimentation and to develop an analytical framework of the positions and vicissitudes in the relations between the youth and consumption. The research was carried out at two public schools in Porto Alegre with 35 young students from fourteen to seventeen years old. The discourse analysis of what was said in the meetings was based on the contributions of Michel Foucault. Many issues emerged in the research process, such as strategies for young people to get money, differentiation and social status due to consumption practices, and the internet as a basic need. We analyze the enunciation "to consume is to spend money" which has become speakable given some historical changes (such as the transformation of our relationship with objects), the position of the young as financial dependents of their parents, among other aspects. We conclude the article arguing in favor of initiatives aimed at an education concerning consumption, sustained in an ethical and political commitment to enable other forms for subjectivation. Furthermore, we think it is a challenge to psychology to provide input to this subject, through the production of knowledge and practices, as the theme still has few studies, at least with regard to youth.
\end{abstract}

Keywords: Consumption, Youth, Intervention Research, Subjectivity Production, Education Concerning Consumption.

\section{Consumo, Dinero y Diferenciaciones Sociales: Dichos de Jóvenes en una Investigación Intervención}

Resumen: En la coyuntura de las discusiones pos-estructuralistas respecto a los procesos de subjetivación, así como de los escritos de autores como Hannah Arendt, Zygmunt Bauman y Jurandir Freire Costa, se reconoce el impacto del consumo, comprendido como práctica social, en la constitución de los sujetos contemporáneos. A causa de ello, realizamos una investigaciónintervención con la finalidad de abrir espacios de discusióny experimentaciones, y esbozar uncuadro analítico sobre los posicionamientos y vicisitudes en la relación jóvenes/consumo. La investigación fue realizada en dos escuelas de Porto Alegre con 35 jóvenes de catorce a diecisiete años. El análisis del discurso relacionado a las contribuciones foucautianas nos ha conducido en el análisis de lo que se ha dicho en los encuentros. En el proceso de investigación surgieron cuestiones como: estrategias de los jóvenes para obtener dinero, diferenciación y status social a partir del consumo, y la internet cuanto una necesidad de primera orden. Entre otros, en ese artigo, analizamos el enunciado "consumir es gastar dinero", que se ha vuelto relevante a partir de los cambios históricos (como la transformación de las nuestras relaciones con los objetos del uso), de la posición del joven cuanto dependiente económico de sus padres y responsables, así como otros aspectos. Cerramos el artículo argumentando a favor de iniciativas destinadas a la educación cuanto al consumo, sostenida en un compromiso ético-político capaz de permitir otros agenciamientos en relación con los actuales modos de subjetividad. Por ello, pensamos que es un desafío para la psicología ofrecer contribuciones por medio de la producción de conocimientos y de prácticas, pues se trata de una temática que tiene estudios muy puntuales, por lo menos a los relacionados a la juventud.

Palabras clave: Consumo, Juventud, Investigación Intervención, Producción de Subjetividad, Educación Cuanto al Consumo. 


\section{Introdução}

O consumo, na acepção de esgotar (alimentos são exauridos para propiciar energia) e na de adicionar (o uso de objetos confere sentidos, marca status, media relações), atravessa tempos e sociedades (Barbosa, \& Campbell, 2006). Contudo, desde a Revolução Industrial, este processo social tornou-se cada vez mais capital, complexo, fluído. Neste sentido, Arendt (2010) sustenta que, ao se alterarem as formas de produção dos objetos de uso, possibilitando sua abundância, esses passaram a ser tratados como se fossem bens de consumo: "em nossa necessidade de substituir cada vez mais depressa as coisas mundanas que nos rodeiam, já não podemos nos permitir usá-las, respeitar e preservar sua inerente durabilidade; temos que consumir, devorar, por assim dizer, nossas casas, nossa mobília, nossos carros" (p. 155-6).

Ainda que existam alguns escritos anteriores importantes (como o livro de Thorstein Veblen (1899/1983) "A teoria da classe ociosa", publicado originalmente em 1899), foi na segunda metade do século $\mathrm{XX}$ que o consumo, como objeto de estudos, ganhou maior consistência. Desde então, análises das ciências sociais e humanas vêm identificando-o como cada vez mais central na compreensão das sociedades e culturas contemporâneas. Assim, em sintonia com as discussões pós-estruturalistas sobre os processos de subjetivação, tal processo social mostra-se assaz relevante na produção da subjetividade, entendida aqui como território existencial em constante criação face à nossa experiência no mundo (Silva, 2003), cujas condições de produção implicam instâncias humanas intersubjetivas, interações institucionais, máquinas sociais, mass-mediáticas, entre outras (Guattari, 2008).

Trata-se de tema controverso, que enseja variadas concepções, algumas bem distintas: análises inspiradas na Teoria Crítica da Escola de Frankfurt marcam a homogeneização das consciências na cultura do consumo (Severiano, 2006); por outro lado, tem-se posições como a de Canclini (2009, p. 114), para quem "el consumo sirve para pensar, en un escenario de disputas por aquello que la sociedad produce y por las maneras de usarlo".

Se o consumo é ou não derivado inequivocamente da produção capitalista e se constitui um fenômeno moderno anterior mesmo à Revolução Industrial são questões que encontram diferentes respostas no campo dos estudos do consumo, como assinala Fontenelle (2014), que aborda um ponto basilar: a par das transformações produtivas, eco- nômicas, urbanas, entre outras, o estabelecimento de uma cultura do consumo só foi factível a partir de uma revolução nas mentalidades. Essa - ocorrida quando as identidades já não eram mais tributárias de um lugar fixo e arbitrário ocupado na sociedade que criaria condições para alguém acreditar "que era possível 'ser outra pessoa' apenas por usar um vestido que sugeria uma conexão com a foto da duquesa X" (Fontenelle, 2014, p. 221). Igualmente crucial para esse tipo de crença florescer e se espraiar no tecido social foi a assunção de certa lógica do consumo, não centrada no valor de uso de produtos e serviços, ou no prazer hedonista proporcionado por esses, mas que acionava, colocava em primeiro plano, processos de significação e comunicação, e de classificação e diferenciação social (Baudrillard, 2010).

Em uma sociedade tradicional, as grandes questões da existência (como viver, pelo que morrer etc.) são dadas como respondidas por suas instituições; a sociedade de consumo não oferece uma resposta, mas muitas, de modo que "qualquer escolha configura um 'estilo de vida', com seus comportamentos, valores, vestuário e hábitos de consumo característicos” (Rocha, 2005, p. 113). Assim, a abertura de um campo prenhe de possibilidades e liberdades constituiu a promessa sedutora da sociedade de consumo. Neste sentido, cabe lembrar, com Saraiva e Veiga-Neto (2009), que, sendo a competição o princípio de inteligibilidade do neoliberalismo, "a governamentalidade neoliberal intervirá para maximizar a competição, para produzir liberdade para que todos possam estar no jogo econômico" (p. 189). Portanto, neste contexto de relações, a liberdade passa a ser também mais um objeto de consumo.

Lazzarato (2006, p. 100) propõe que "consumir não se reduz mais a comprar e a 'destruir' um serviço ou um produto, como ensina a economia política e sua crítica, mas significa sobretudo pertencer a um mundo". Já Rocha (2005) levanta a hipótese de que o verdadeiro objeto de consumo (na acepção de coisa e objetivo) não são os produtos, estilos de vida ou sensações associadas a eles, "mas a própria subjetividade que é deste modo produzida. Ao consumir, criamos para nós mesmos uma biografia" (p. 116).

Não há como negar que a atual lógica e tecnologias do consumo - entre outras, a publicidade, o sistema financeiro, a mídia, as redes sociais digitais - impactam a constituição dos sujeitos contemporâneos. Em função disso, pensamos que cabe à Psicologia, em especial à Psicologia Social, buscar compreender e problemati- 
zar as linhas de captura que estão se formando e abrir espaços a linhas de fuga que possam traçar outras formas de existir (Deleuze, \& Guattari, 2007).

Embora concirna a todos nós, interessa-nos as vivências e posicionamentos dos jovens em relação ao consumo e suas tecnologias. Visto sobreposições e diferenças conceituais, algumas considerações são pertinentes. Análises referem tanto a juventude (Debert, 2010; Kehl, 2004) quanto a adolescência (Rocha, \& Garcia, 2008) como valor e ideal cultural contemporâneo. Coimbra, Bocco e Nascimento (2005) contrapõem os conceitos de adolescente/adolescência e de jovem/juventude e, em função dos contextos de emergência e das implicações teórico-políticas, optam pelo uso do segundo, que não guardaria, no seu entender, correspondência com certa faixa etária. Ressalte-se que todos estes trabalhos apontam a incidência da sociedade ou cultura do consumo na produção subjetiva do jovem ou do adolescente.

Mattos e Castro (2008, p. 152) afirmam que "jovens e cultura do consumo são temas que estão próximos nas discussões e nos debates contemporâneos". Contudo, há que se examinar como e o que vem sendo pautado neste âmbito na academia. Essas autoras, por exemplo, discutem os sentidos que a liberdade adquire no contexto da cultura do consumo para os jovens em função do que emergiu em uma série de pesquisas que realizaram, mas cujo objetivo era outro, a saber, investigar as suas relações sociais na cidade.

A fim de conhecer pesquisas e análises já desenvolvidas, realizamos em janeiro de 2016 busca de artigos no portal SciELO (Scientific Electronic Library Online) a partir da composição "consumo + juventude" e "consumo + adolescência" (índice assunto) e o retorno foi muito baixo; então, fixamos consumo (índice assunto) e compusemos, um a um, com juventude, jovens, jovem, adolescência, adolescentes, adolescente (todos os índices). Excluídas redundâncias e escritos não pertinentes (consumo de oxigênio, estudos com animais etc.), chegamos a 308 artigos. Sua revisão integrará outro escrito, mas cabe trazer algumas constatações: há muito mais estudos relativos à adolescência e variações; apesar do número expressivo, as temáticas são assaz reduzidas, resumem-se a três, a saber: consumo de alimentos $(41,9 \%)$, de álcool e tabaco (30,5\%), e de outras drogas - ilícitas ou controladas (18,5\%); só 28 trabalhos $(9,1 \%)$ tecem discussões concernentes à sociedade e/ou cultura do consumo, abordando temas como trabalho, crime, identidades, beleza, consumo cultural, midiático ou de produtos/serviços; esse tipo de discussão aparece majoritariamente em artigos que utilizam o termo juventude (15 dentre os 28 localizados).

Uma vez que o SciELO reúne importantes revistas das ciências humanas, sociais e da saúde - inclusas as mais bem avaliadas do campo da Psicologia -, com base no quadro resumido esboçado acima, fica patente que os estudos já realizados (por pesquisadores das mais variadas áreas) giram em torno do consumo de substâncias, com acento em processos patológicos e/ ou que têm incidência direta sobre o corpo (obesidade, drogadição, entre outros). Trabalhos pertinentes e essenciais, sem dúvida. Contudo bastante pontuais em face da magnitude e complexidade encerrada na questão do consumo na contemporaneidade.

A contribuição de nossa pesquisa segue outra direção. Entendemos que o consumo imiscuiu-se continuamente, a ponto de tornar-se, de forma paradoxal, quase transparente - no que poderia ser chamado "vida ordinária" dos jovens, produzindo efeitos nos seus modos de ser, pensar, sentir e se relacionar. E, como o consumo torna-se tão natural e familiar, resta que pouco interrogamos nossas práticas neste âmbito, de modo a poder pensá-las e senti-las, e, talvez, alterá-las. Em função disso, realizamos a pesquisa-intervenção intitulada "Vivências de consumo e crédito: partilhar e operar para criar práticas outras", que teve como objetivo, por um lado, abrir um espaço de discussão e experimentações aos jovens e, por outro, esboçar um quadro analítico sobre os posicionamentos e vicissitudes da relação juventude/ consumo no contemporâneo. No seu horizonte está a proposta do desenvolvimento de iniciativas em direção a uma educação quanto ao consumo, que constituiria um espaço para a problematização dos modos de relação postos no mundo contemporâneo que propõe a todos - talvez em especial para os jovens - uma existência para consumo(s).

\section{Método}

Este estudo teve como norte teórico-metodológico a perspectiva da pesquisa-intervenção, que se baseia na noção de que "todo dispositivo de pesquisa transforma o que se deseja pesquisar" (Castro, 2008, p. 29). Na mesma linha, Rocha e Aguiar (2003) apontam que com sua ação crítica e de implicação do pesquisador, a pesquisa-intervenção "amplia as condições de um trabalho compartilhado" (p. 71). 
No que diz respeito à pesquisa-intervenção no campo da juventude, Castro (2008) ressalta ser fundamental assegurar a relevância da pesquisa para os próprios jovens, e propõe que "estabelece-se um processo cujo ponto de início formal, dado pela entrada dos pesquisadores no campo, é sempre resignificado e reestabelecido, à medida que outros lugares de enunciação são produzidos, estabelecendo rupturas, desvios e deslocamentos, tanto individuais, como coletivos" (p. 38).

Adotamos referenciais teóricos da perspectiva ético-estética em Psicologia Social (Silva, 2003), particularmente o trabalho de Michel Foucault e pensadores associados; seu intuito foi produzir "uma investigação participativa que busca a interferência coletiva na produção de micropolíticas de transformação social" (Aguiar, \& Rocha, 2007, p. 649). Por meio do processo de pesquisa, buscamos oportunizar aos jovens a problematização da realidade sociopolítica que os cerca, incitando-os a refletir acerca da esfera do consumo, bem como áreas e questões associadas surgidas como objeto de discussão nos encontros.

A estratégia de trabalho utilizada consistiu na realização de Rodas de Conversa que, de acordo com Afonso e Abade (2008), fundamentam-se em um modelo de intervenção pontual que visa construir condições de troca entre os participantes por meio da escuta e da circulação da palavra, orientando-se na promoção da reflexão acerca dos temas discutidos. Tal forma de trabalho nos parece pertinente a um processo educativo que se quer mais horizontal, como pensamos que deve ser uma educação quanto ao consumo.

Participaram das Rodas de Conversas 35 jovens de 14 a 17 anos, de ambos os sexos, que à época cursavam o primeiro ano do ensino médio em duas escolas públicas de Porto Alegre. Na primeira escola, os encontros ocorreram com um grupo de nove estudantes, em turno inverso ao de aula, no segundo semestre de 2014; na segunda, os encontros foram realizados com dois grupos de estudantes, com 15 e 11 participantes, como parte da disciplina de História, no primeiro semestre de 2015. Ressalte-se que a frequência de alguns dos jovens não foi regular, mas, mesmo que tenham participado somente em um ou dois encontros, suas posições ressoaram junto aos demais e vice-versa, houve afetação e, por isto, entendemos que constituem contribuição relevante para as análises.

A partir da apresentação da pesquisa para as turmas indicadas pela escola, os jovens que se interessaram em participar foram instruídos a conversar com seus pais ou responsáveis a fim de obter a concordância desses mediante assinatura do Termo de Consentimento Livre e Esclarecido, em consonância com as normatizações éticas vigentes. Conforme combinado com os participantes, as falas foram gravadas.

Com cada um dos três grupos foram realizadas quatro encontros, com periodicidade semanal e duração aproximada de 50 minutos. No primeiro, a proposta era a conversa livre e compartilhamento de vivências acerca do consumo - as trocas foram estimuladas por nós por intermédio de perguntas como "O que vocês entendem como consumo?", "O que leva vocês a consumir?", entre outras similares. Nos minutos finais, para obter subsídios para a atividade da semana seguinte, pedimos para que eles referissem produções publicitárias que lhes instigaram de algum modo. Assim, o segundo encontro iniciou-se com a apresentação dessas publicidades e de outras retiradas da programação de televisão aberta e/ou da internet. As peças (cenas de um mesmo comercial agrupadas ou anúncios promocionais de páginas na internet) foram impressas em folha A4 para que os jovens pudessem intervir no material, tendo como inspiração The Bubble Project (2014). O objetivo era que os jovens "dialogassem" com o veiculado utilizando balões (como os de uma história em quadrinhos) em branco disponibilizados por nós, estabelecendo um movimento de resposta à publicidade. No terceiro encontro, crédito e endividamento foram objeto de discussão. A ferramenta disparadora foi a história em quadrinhos "Turma da Mônica em Superendividados... até a raiz do cabelo" (Maurício de Souza Produções, 2009) - desenvolvida em comemoração aos 20 anos do Código de Defesa do Consumidor - que traz, entre outras questões, o consumo supérfluo (e a moral associada), o uso dos cartões de crédito e a dívida familiar. Após sua projeção e leitura, além de trazerem suas impressões sobre aquela narrativa, os participantes compartilharam histórias vividas ou conhecidas, fizeram questões e tiraram dúvidas com relação à temática do crédito. $\mathrm{O}$ último encontro foi dedicado à questão dos movimentos críticos em relação ao consumo, trabalhados a partir de conceitos que tangenciam as discussões contemporâneas nesse âmbito, tais como sustentabilidade, desperdício, consumo consciente, responsabilidade social, cidadania, entre outros. Após receberem cartões com essas expressões, os jovens foram convidados a produzir, individualmente ou em parceria, 
materiais como colagens, cartazes, textos e desenhos que remetessem a um ou mais conceitos. No fim desta atividade, o compartilhamento das produções deu ensejo para que eles pudessem externar suas compreensões e/ou sanar possíveis dúvidas com relação aos termos utilizados. Cabe pontuar que, apesar das abordagens temáticas propostas por nós terem se mantido comuns nos três grupos, cada qual mostrou movimentos próprios, engajou-se de forma diferencial, fazendo o seu processo, o que não é só acolhido como esperado em uma pesquisa-intervenção.

O trabalho com os grupos resultou em um extenso material para análise, constituído das transcrições das falas e das produções gráficas realizadas pelos jovens. Neste artigo, vamos lançar mão apenas das suas falas, com a seguinte identificação: cada participante será referido pela letra "J", de jovem, numerada de 1 a 35 , de acordo com a ordem em que realizou sua primeira participação (assim, J1 a J9 são alunos da primeira escola; J10 a J24, do primeiro grupo da segunda escola; e J25 a J35, do segundo grupo da segunda escola).

Utilizamos como recurso metodológico analítico neste trabalho a análise do discurso pautada nas contribuições foucaultianas (Foucault, 2000, 2014; see also Fischer, 2001). Ressaltamos que, para o filósofo, em "A arqueologia do saber", o discurso é constituído por um conjunto limitado de enunciados que foram efetuados desde determinadas condições de existência. Procuramos, então, trazer à análise aquilo que foi dito pelos jovens sem qualquer intenção de "revelar" ou estabelecer "o" sentido verdadeiro do que foi falado. Importa-nos, antes, trabalhar na sua superfície, multiplicando o discurso, extraindo alguns enunciados e colocando-os em relação a outros, deixando, assim, aflorar as contradições, as diferenças, os apagamentos, em suma, permitindo aparecer a heterogeneidade própria aos diferentes campos discursivos que transversalisam a temática do consumo. Operacionalmente, primeiro nos debruçamos sobre o que foi dito, ou seja, as enunciações; durante esse trabalho, enunciados que atravessavam as falas foram se destacando; então, buscamos multiplicá-los, abordando suas condições de existência e discutindo os modos de subjetivação que engendram.

\section{Resultados e discussões}

O feedback recebido quando à intervenção foi bem positivo; poder conversar sobre consumo, "dialogar" com as publicidades, perguntar(-se) acerca de questões financeiras, entre outros aspectos, foram mencionados (durante os encontros e no fecho no último dia) como pontos interessantes do trabalho. Sendo assim, entendemos que a pesquisa atendeu seu objetivo de propiciar reflexões - que, quem sabe, puderam abrir aos jovens participantes espaços para formas outras de ser e habitar um mundo onde o consumo mostra-se tão central.

No que concerne ao objetivo de traçar um quadro analítico sobre juventude e consumo no contemporâneo, cabe uma elucidação. Apesar de a intervenção ter resultado em um rico material que dá ensejo a diversas análises, essas são circunscritas - acima de tudo, por termos feito um recorte considerado somente idade e vínculo com escola pública. Consideramos que marcadores sociais como condição familiar e socioeconômica, raça/etnia, gênero, entre outros, trazem vivências, questões e prismas outros na construção subjetiva dos jovens no que tange ao consumo. Contudo, por se tratar de uma primeira aproximação ao tema, buscávamos provocar o pensar e, baseados no emergente, mapear o que se apresentava - para em novos estudos nos debruçarmos sobre as singularidades das diferentes condições do ser jovem.

A proposta reverberou e, face às nossas provocações em cada encontro, o debate fluiu na direção que os participantes julgaram mais interessante, trazendo à baila questões como: relações entre consumo e vaidade, diferenciação e status social a partir do consumo, estratégias para obter dinheiro e adquirir/ acessar produtos e serviços, contraponto entre básico e não básico, o "sentido" de certas publicidades, as condições para poderem se sustentar de forma independente, a internet enquanto necessidade de consumo equiparada à água ou luz. Neste artigo, buscamos, com a discussão de certos enunciados, mostrar articulações entre algumas dessas questões.

Na primeira roda de conversa, ao serem convidados a falar acerca do que lhes vinha à mente a partir da palavra consumo, alguns jovens usaram expressões como comida, lanches, roupa, gasto de energia, ganância etc. Na sequência, tão logo começaram a falar sobre o que entendiam ser consumir, fez-se presente, nos três grupos, o enunciado "Consumir é gastar dinheiro" (J1, J19, J23, J34, J35), sobre o qual entendemos ser importante multiplicar relações, ou seja, interrogar suas condições de dizibilidade.

Os primeiros ditos remetem, majoritariamente, a materialidades, a uma face "objetiva" do consumo; a 
menção ao dinheiro apontaria só mais uma - ou marca relações, indica uma lógica? De início, fundamental atentar para quem fala: jovens estudantes que não têm renda própria. Ao longo dos encontros, eles referiram estratégias de que lançam mão para obter dinheiro a fim de ir ao cinema e/ou lanchar com amigos, adquirir uma roupa ou assistir a um show desejado e "caro": ajudar ou fazer "favores" para familiares (J2, J22, J23), tirar "boas notas" e "se comportar bem" como elemento de barganha (J1, J3, J4), economizar de forma a pedir somente parte do dinheiro, o que acham que soa mais convincente (J1, J2, J4). Evidencia-se a posição de dependente financeiro desses jovens e as condutas que passam a assumir em função disso.

Uma vez que o sujeito do discurso não remete ao sujeito em si, mas a um lugar de dispersão, o conceito de polifonia discursiva (Fischer, 2001) é útil para entender outras vozes que podem estar constituindo este enunciado: as de seus pais ou responsáveis, cujo dinheiro os jovens precisam para consumir e que, no jogo de relações intersubjetivas, lhe repassam sob certas condições. Cabe lembrar que, para Foucault (1999), as relações de poder são imanentes a quaisquer relações: em uma agonística entre sujeitos livres, cada qual busca conduzir condutas de outrem. Assim, pode-se conjeturar que, face aos pedidos dos jovens, aconteçam embates acerca de quanto eles gastam (já gastaram, vão gastar), no que, sua pertinência etc., fazendo desta uma questão "primeira". Neste sentido, no caso dos jovens, a (tão decantada) liberdade - de escolha na sociedade de consumo (Rocha, 2005) e de participar do jogo econômico neoliberal (Saraiva, \& Veiga-Neto, 2009) - é uma dimensão "sob tutela", cujas implicações ainda carecem de estudos.

Neste mesmo enunciado se atualizam outros tipos de relações e lógicas. Para que consumir - noção que remete a uma pletora de significações - possa ser dito equivalente a gastar dinheiro, ato econômico com implicações sociais, foram necessárias certas condições históricas, econômicas, sociais etc. Como já referido, Arendt (2010) marca uma mudança crucial no modo de relação com os objetos de uso. Se até a Revolução Industrial esses eram produzidos na expectativa de serem duráveis e com a finalidade de enriquecer o mundo, com sua crescente disponibilização, o seu tempo de uso abreviou-se a ponto de serem consumíveis e consumidos como se alimentos fossem. Em função disso, para Costa (2004), o consumo deve ser compreendido enquanto metáfora, que faz referência “à rapidez com que adquirimos novos objetos e inutilizamos os velhos. Ou seja, tratamos os objetos industriais como tratamos substâncias que se prestam à reprodução dos ciclos biológicos, donde a assimilação do ato de compra ao ato de consumir" (p. 78).

A efemeridade daquilo que é consumido passou a ser tal que tornou dizível "consumir é gastar dinheiro", enunciado no qual os objetos e/ou os serviços estão ausentes ou ficam em segundo plano, como se fossem irrelevantes. Bauman (1999), neste sentido, ressalta que, na atual sociedade de consumidores, as coisas não são objeto primeiro do consumo, pois os consumidores "são colecionadores de coisas apenas num sentido secundário e derivativo" (p. 91). Traçar tais considerações não significa advogar que os jovens não desejam, valorizem e/ou usufruam produtos ou serviços, mas visa discutir algo que se realçou: o consumo enquanto ato que tem por decorrência a circulação do dinheiro - condição de funcionamento e incremento do modo capitalista.

Nesse, todos são constantemente incitados a ter participação ativa no mercado. Para evitar estagnação e almejar crescimento, faz-se necessária ao sistema capitalista neoliberal a intensificação de cada um de seus fluxos. Se Deleuze (2008) assinalou que não tínhamos mais "um capitalismo dirigido para a produção, mas para o produto, isto é, para a venda ou para o mercado" (p. 223-224), diferentes autores (Chesnais, 1995; Guttmann, 2008) apontam que o que vigora atualmente é um capitalismo financeiro, no qual o capital faz dinheiro sem sair da esfera financeira. Lazzarato (2012) dá um passo adiante: "no neoliberalismo, o que, de modo reducionista, chamamos 'finanças' é indicativo da força crescente da relação credor-devedor" (p. 23, tradução nossa). Assim, o dinheiro, sua "circulação-venda" - na forma de cartões de crédito, de crédito ao consumo, por exemplo -, ganha grande relevo, é muito estimulada, pois estratégica, uma vez que constitui fonte de lucros sem par (Bauman, 2010).

No contemporâneo, consumir significa aderir a um universo (Lazzarato, 2006) e delineia quem se é (Rocha, 2005), assim, ter - ou gastar - dinheiro acaba configurando-se como um importante vetor de subjetivação. Neste sentido, duas condições/posições foram traçadas por alguns jovens: ser pobre e ser rico - polarizadas, mas com certas nuances. $\mathrm{Na}$ primeira condição, a marca fundamental é a falta de recursos: "Pobre também gosta de gastar, só que ele não tem o que gastar" (J23, grifo nosso). Esse último 
aspecto não é visto/dito como um obstáculo ao consumo, que passa a se realizar atrelado ao endividamento: "Pobre gasta o que não tem, aí fica devendo" (J23, grifo nosso).

Fontenelle (2014) assinala que, apesar do endividamento como base para o consumo sempre ter sido central na organização do capital, o que temos hoje é "uma sofisticação dos métodos de financeirização da economia, que, por seu turno, tem levado a uma radicalização do processo de endividamento, visando dar conta das contradições do capital” (p. 228). Na fala acima reproduzida, chama atenção que pobreza e endividamento são naturalizados, como se concernissem apenas ao indivíduo (e não a todo um sistema social-político-econômico que fomenta o consumo via endividamento, sem falar na pobreza). Além disso, sua associação recebe uma conotação moral (Hennigen, \& Borges, 2014), pois é dito decorrente da ação (que soa condenável) de alguém que gosta de gastar e gasta o que não tem.

O que é dito acerca da posição/condição "ser rico" também recebe contornos morais. Aquele que tem recursos significativos para consumir pode ou não demonstrar a riqueza, transitar entre diversos espaços, utilizar ou não diferentes produtos, vestir-se como desejar, optar ou não por usar transporte público. Dentre outras, destacamos as falas: "Eu conheço pessoas que são ricas, mas que não demonstram isso, elas são totalmente humildes" (J3);

Eles [os ricos humildes] não ostentam. Se tiver que ir num lugar mais simples, eles vão, se for num chique, eles vão. Tem gente do colégio mesmo, que não tem condição, mas tem um Iphone. Eles não, eles têm um celular simples, se vestem de maneira simples. Andam de ônibus, coisas assim (J4, grifo nosso).

Atualmente, todos são incitados pela máquina capitalista a consumir e, assim, cada um de nós "pode desejar ser um consumidor e aproveitar as oportunidades que esse modo de vida oferece. Mas nem todo mundo pode ser um consumidor. [...] Todos nós estamos condenados à vida de opções, mas nem todos temos os meios de ser optantes" (Bauman, 1999, p. 94). É interessante notar que, para estes jovens, gostar de gastar (ou seja, de consumir) não diferencia ricos de pobres (que também gostam). O que os contrapõe é que, se para esses consumir associa-se ao endividar-se, para aqueles consumir é tomado como um exercício da liberdade. E sobressai uma imagem de ricos totalmente humildes e simples - bastante idealizada. Focando na superfície do discurso, pode-se pensar que essas características estão ali a iluminar um aspecto: a ostentação ou demonstração do que se possui. Aqui os jovens parecem repercutir toda uma discursividade moralizante do consumo hedonista de quem está na chamada base da pirâmide (Hemais, Casotti, \& Rocha, 2013) - os "pobres" -, pois há referência a pessoas do colégio que não têm condições, mas têm Iphone.

Sem entrar na polêmica questão da ostentação (see Calligaris, 2008; Pereira, 2014), cabe referir Bragaglia (2010, p. 109), que elenca a "busca de prazer emocional por meio do uso das mercadorias/marcas como comunicadores sociais", a fim de obter distinção, inserção em grupo ou outro, como um dos motores para os comportamentos de consumo. Tal aspecto emergiu em diferentes momentos, como quando a vaidade entrou em discussão, em que ficou patente a importância que tem a percepção que o outro desenvolve a partir do que se porta/usa. No que tange ao que vínhamos analisando, uma participante aponta que muitos desejam escapar da imagem de pobre. Ela comenta que há jovens que não gostam de repetir as mochilas de um ano para o outro. Ainda que esteja em bom estado, utilizar a mesma mochila pode ser percebido, de acordo com ela, como um indicativo de que se é "pobre": "todo mundo já te viu com ela e daí tu 'ah vão pensar que eu sou pobre [fazendo o sinal de aspas com as mãos] porque tava com a mesma mochila do outro ano'” (J25).

Por meio do consumo/uso do que aparece como novo, os jovens buscam certa diferenciação social visando escapar do estigma daquele que é tido como pobre. Podemos entender que o "pobre" mencionado pelos jovens, mais do que uma condição socioeconômica, diz respeito a uma forma de ostracismo social na sociedade de consumidores, na qual a capacidade enquanto consumidor define o status pessoal e cidadão, a possibilidade de ser, conforme propõe Bauman (2008), a própria pessoa, uma mercadoria desejável/ vendável no mercado das diferentes relações (trabalho, amorosas etc.).

Em meio à discussão acerca de ser rico e/ou pobre e gastar, emergiu a relação entre o consumo e a opção por ter filhos: "Muitas pessoas deixam de ter filhos para não gastar mais, porque acham que é consumo" (J22). Sem referir outras possibilidades (de ordem afetiva, como ter filhos é aprender a 
amar, ou religiosa, como ter filhos é uma benção de Deus), o que se enuncia fecha-se em torno da lógica do mercado. Foucault (2008), ao discorrer sobre o desenvolvimento do neoliberalismo americano, pontua que, em nome do incremento do chamado capital humano, os filhos passaram também a entrar na esfera de cálculo econômico. Deste modo, forja-se todo um discurso acerca "de investimentos e retornos" que perpassa hoje o tecido social, contribuindo para a produção de posições subjetivas nas famílias. Neste sentido, alguns jovens se identificaram com a posição daquele que extrai recursos dos pais ou provedores, ressaltando uma diferença no tempo: "Hoje em dia filho exige tudo quanto é coisa. Eu mesmo exijo. Eu estou sempre pedindo roupa toda hora, ou celular. Então, comparando com antigamente, era mais fácil ter filho antigamente" (J19).

Ao ocupar a posição daquele que depende dos recursos de outrem - mãe, pai, avó etc. -, os jovens deparam-se com limitações. Assim, para poder expandir seu consumo ou não o restringir ao que seus provedores oferecem ou permitem, o trabalho entra em cena. Alguns poucos disseram já trabalhar (esporádica ou continuamente) e outros colocaram ter interesse ou serem instigados a trabalhar em um futuro não muito distante: "O que vai acontecer para eu conseguir dinheiro é começar a trabalhar. Daí eu vou poder comprar as coisas que eu quero sem estar pedindo pro meu pai" (J7); "Minha mãe não me dá, ela diz que eu tenho que arranjar um trabalho porque eu sou muito encostada" (J12);

Hoje em dia quem sustenta o meu consumo são os meus pais e eu quero estudar e trabalhar para mim sustentar o meu consumo [...] Tem algumas coisas que eu quero que meus pais não têm condições. Então eu vou trabalhar e eu vou juntar dinheiro para poder consumir o que eu quero (J19).

O trabalho, nos ditos dos jovens participantes da pesquisa, não está atravessado pelas noções de vocação ou de dever prescrito pelo divino, elementos discursivos de outrora. Diferentemente da ética protestante, descrita por Weber (1983), o trabalho aqui não tem um fim em si mesmo, mas aparece enquanto meio para possibilitar um maior consumo. Uma das participantes deixa isso bem explícito: "Tu vai para a escola para arranjar um emprego bom para quê? Para consumir cada vez mais. [...] Qual teu objetivo de vida? Ter um trabalho bom, um emprego bom para fazer dinheiro para consumir coisas" (J17).

Tal convergência da vida para o consumo constitui um modo de existência que se produz face aos constantes incitamentos presentes na sociedade atual. Ao retomar Pierre Boudieu, Bauman (2008, p. 116) afirma: "a coerção tem sido amplamente substituída pela estimulação, os padrões de conduta antes obrigatórios, pela sedução, o policiamento do comportamento, pela publicidade e pelas relações públicas, e a regulação normativa, pela incitação de novos desejos e necessidades". Pensamos que refletir sobre este modo de existência, suas formas de captura e implicações, pode criar aberturas para outras formas de viver. Neste sentido, apostamos em uma educação quanto ao consumo, a se constituir como uma prática reflexiva e problematizadora, o que abordamos mais adiante.

Quanto ao que se consome, ou se busca consumir, os jovens categorizaram em um esquema de dois polos opostos. Em diversos momentos, fizeram referência ao consumo do "necessário", do "básico" e do que "se precisa", muitas vezes contrapondo diretamente ao consumo do "não necessário", do que "não se precisa" e do "excessivo". Já no primeiro encontro (logo, antes da introdução da historieta da Turma da Mônica na qual tais polaridades encontram eco), jovens dos diferentes grupos lançaram mão de tal dicotomia. Um, ao comentar o comportamento dos filhos nos dias de hoje, disse: "Antes se contentavam com o básico, agora querem o que não precisa" (J14). A própria alimentação foi dita necessária quando era aquela do dia a dia, porém, "sair para jantar fora às vezes não é necessário” (J35).

Mattos e Castro (2008) pontuam que a discussão sobre o que seriam as necessidades "naturais" e as "artificiais" do homem está ultrapassada. As autoras marcam uma virada em direção à consideração do bem-estar individual: "a relação entre o objeto de desejo e o que é consumido (o objeto útil) não se estabelece segundo qualidades intrínsecas das coisas que chamamos de úteis, mas segundo o prazer proporcionado individualmente por esse objeto" (p. 158). A despeito disto, as falas dos jovens atualizam um discurso que se faz muito presente quando, por exemplo, se orientam consumidores em caso de endividamento em programas jornalístico-educativos, em cartilhas de PROCONs (Programa de Proteção e Defesa do Consumidor) ou outros espaços na chamada educação para o consumo ou do consumidor. Porém, há uma 
"exceção" significativa. Ao lado de produtos/serviços ditos básicos (água, luz, aluguel, comida), figura a internet, um serviço não usualmente desse modo. Um dos participantes explica:

Internet é um meio de comunicação com os teus amigos e tu pode se comunicar com qualquer pessoa. É um jeito que tu tem de se expressar, digamos tu te sente reprimido em se expressar pessoalmente com a pessoa, pela internet às vezes tu consegue. É mais fácil. Então a internet é um modo de consumo que todo mundo usa mesmo que indiretamente e podefalarque não é necessário, mas, se ficar uma semana sem internet, pode acabar digamos que enlouquecendo sem a internet. Então a internet é um meio bem importante (J5, grifo nosso).

Com que voz esse jovem está dialogando? Quem diz que não seria necessário? Talvez com seus pais ou com os operadores de certa educação do consumidor. E, por tabela, também conosco, pesquisadores que estavam propondo conversas sobre o tema consumo: não seriamos nós, eventualmente, agentes de um saber moralizador das práticas de consumo? Assim, não podemos descartar que o "politicamente correto", como a crítica ao chamado "supérfluo" (que buscamos trazer com a historieta da Turma da Mônica para poder problematizar) tenham perpassado os ditos dos jovens. Contudo, assim como na fala acima, acreditamos que eles não deixaram de expressar e marcar posições importantes "de fato" na sua vivência; o fluir de pensares - não a indicação de uma posição - quis ser a tônica do trabalho de pesquisa desenvolvido.

$\mathrm{O}$ acesso à internet oportuniza, como ressaltam Schwertner e Fischer (2012, p. 413), "uma espécie de pertencimento fundamental para as novas gerações". Espaço privilegiado de comunicação, a internet também cumpre hoje um importante papel na vida dos jovens, qual seja: o de propiciar algum nível de emancipação em relação aos familiares. Segundo Canclini (2009), o trabalho, o estudo e o matrimônio constituem meios tradicionais no processo de se independizar daqueles que são responsáveis pelos jovens desde sua infância. Atualmente, na adolescência, a conectividade e o consumo, sem substituir os meios de independização anteriores, mas articulando-se a eles, antecipam vivências estrangeiras ao núcleo familiar. Outros mundos, acessíveis por meio dos diversos dispositivos conectados à rede, podem ser alcançados e vivenciados inclusive dentro do próprio quarto, sem a necessidade de sair de casa. Portanto, ao dizer a internet uma "necessidade básica", os jovens nos permitem vislumbrar uma mudança importante dos processos de subjetivação.

No rol do consumo não "básico" ou que "se precisa", os jovens referiram uma série de gastos nas atividades para estar entre amigos, como ida aos shoppings, ao cinema, os lanches, o refrigerante nos passeios, uma roupa ou mochila nova, os doces, entre outros. Kehl (2004) entende que os espaços próprios de frequentação adolescente e os objetos de consumo são espécies de substitutos aos ritos de iniciação na vida adulta de culturas pré-modernas, assinalando que "os acessórios compõem a mascarada adolescente" (p. 95), ajudando na tarefa de reinscrever o novo corpo no novo lugar que ele passa a habitar. Neste sentido, é pertinente colocar que, quando falam deste tipo de consumo, um binarismo bastante interessante se apresenta: gastar com "o que se deve" e gastar com "o que se quer".

Ao mesmo tempo em que apontam limitações para consumir o que desejam - "dinheiro é pouco para o que a gente quer" (J3) -, alguns dos jovens indicam que os objetos que desejam consumir não só se substituem um ao outro rapidamente, mas também podem se multiplicar indefinidamente:

No meu aniversário fui lá e consegui dinheiro, daí comprei um All Star. Daí, nesse fim de semana, eu já queria outro All Star. [...] Cada vez tu quer mais e mais usar um All Star porque é uma cor diferente. [...] Então, o consumo, consumismo, comprar uma coisa que tu gosta, tu vai querer comprar mais ou querer daquilo um pouco diferente. [...] Então consumo acho que gera consumo. Celular tu compra, vai querer um agora e já lançou outro (J19).

Essa mesma jovem acredita que aqueles que "se contentam com pouco" conseguem viver bem, mas "não aproveitam tanto quanto as pessoas que consomem bastante. Tipo, quem consome bastante consegue aproveitar mais, curtem mais". Atualiza-se aqui o imaginário de que "curtir" a vida está atrelado e na dependência, diretamente proporcional, do consumo. Seguindo o raciocínio de Costa (2004), podemos supor que isto se dê justamente porque, em nossa época, a busca do ideal de prazer corporal ou 
do prazer das sensações ocupa um lugar privilegiado na constituição das subjetividades. Como um mesmo objeto não é capaz de manter sua capacidade de despertar excitações sensoriais, busca-se substituí-lo para continuar obtendo felicidade por meio das sensações. De acordo com o autor, são justamente nossos ideais de felicidade que "nos empurram para a aquisição permanente de objetos que, ao ser adquiridos, já portam o signo da obsolescência" (p. 84).

No que tange ao constante incitamento para se buscar mais e mais, cabe destacar, por fim, uma fala que, apesar de assemelhar-se com o muitas vezes posto, traz um diferencial importante em função do contexto que lhe é associado. Ao comentar tal questão, um dos jovens confere uma maior visibilidade a um enunciado que circula na sociedade - que lhe atravessa e marca, pois proferido por professor: trata-se de uma espécie de "palavra de ordem" de que não se deve contentar com pouco, com o que se tem.

Todo mundo fala assim que a mídia influencia porque os atores de TV tão em um padrão e tu tem que ter isso, tem que ter aquilo e tem que ter mais, não pode se contentar só com aquilo. Tem que sempre buscar mais, até professor muitas vezes vive dizendo isso para aluno (J14, grifo nosso).

Poder-se-ia remeter tal enunciado - não se contentar, buscar mais - somente à esfera do consumo de produtos e serviços. Contudo, já há um bom tempo, e de modo crescente, é mais do que isso, há uma diferença nevrálgica: o que está em jogo é um modo de funcionamento no qual cada um é convocado a operar em sincronia com a lógica do mercado. Foucault (2008) propõe que, a partir do empuxo do neoliberalismo americano, passamos à condição de "empresário de si mesmo" (p. 311), incessantemente convocados a produzir de forma a aferir renda do capital que somos para nós mesmos. Com outro mapa analítico, Bauman (2008) ressalta, como já indicamos anteriormente, que na sociedade de consumidores seus próprios membros tornam-se mercadorias. Seu maior desafio e tarefa, segundo ele, é fazer de si mesmo uma mercadoria vendável. Para isto, é necessário "obter qualidades para as quais já existe uma demanda de mercado, ou reciclar as que já se possui, transformando-as em mercadorias para as quais a demanda pode continuar sendo criada" (p. 75). Sustentamos que jovens que "vivem escutando" tais convocatórias - também de seus professores - merecem nossa atenção e oportunidades para construir outros discursos e formas de ser e viver.

\section{Considerações finais}

Para lograr mobilidade e êxito social, que atualmente parece traduzir-se em maior visibilidade individual e maior usufruto de produtos e serviços, é demandado ao jovem - e a todos nós - que aumente sua potência para produzir e intensifique seu ritmo de consumo, tudo isto em meio a um amplo mercado no qual a concorrência não deixa espaço para aqueles que não se adequam ao ritmo frenético e de crescente intensidade. "Contentar-se" com o que se é ou com o que se tem implica assumir o risco de perder a capacidade de tornar-se e/ ou manter-se competitivo. "Obsolescência pessoal" é um espectro a ser temido.

Ter uma vida para o consumo é um modo de existência que responde aos constantes incitamentos do mercado, cuja lógica “vazou” para a vida. É diante desse cenário que as intervenções ao longo dos encontros foram realizadas. Buscamos, justamente, abrir brechas para problematizar o modo, que quer ser hegemônico, por meio do qual as subjetividades são produzidas na sociedade contemporânea. O norte era criar possibilidades para que os jovens se pensassem, sentissem e, eventualmente, agissem de outras formas.

Como já anunciamos, trata-se de propor movimentos e trabalhos para a construção de uma educação quanto ao consumo, sustentada por um compromisso ético-político de, sobretudo, possibilitar outros agenciamentos e formas de subjetivação diante dos modos de relação postos hoje. Neste sentido, tal prática se distanciaria de iniciativas de empoderamento dos consumidores através de disponibilização de informações quanto a direitos e deveres no âmbito das relações de consumo, como as realizadas por PROCONs e outras instituições, ou daquelas existentes no âmbito da Estratégia Nacional de Educação Financeira (Brasil, 2016). De modo algum tomamos essas como não pertinentes; elas podem ser importantes ao mostrar como habitar melhor a sociedade de consumo. Mas nos interessa, fundamentalmente, fraturar, em movimentos micropolíticos, tal lógica de existência - de modo a criar diferentes possibilidades aos jovens - e, para isto, é preciso constituir espaços para pensar e sentir outramente.

Em sintonia com Schwertner e Fischer (2012), concebemos o jovem não como alguém que está definitivamente capturado pela máquina capitalista, mas “como criador e até mesmo agente de transformação 
das formas de vida de que fazem parte" (p. 397). Pois, como nos ensinou Michel Foucault ao longo de sua obra, se há relações de poder, é porque há condições para práticas de liberdade.

Assim, se, por um lado, nas rodas de conversas, observamos a reprodução de enunciados nos quais o jovem é colocado e se coloca em uma posição "estereotipada" de consumidor, por outro, os jovens participantes engajaram-se também em debates reflexivos, compartilhando experiências e estratégias de consumo, às quais apontavam para potentes movimentos de singularização. Caberia a uma educação quanto ao consumo lançar provocações para a expansão desses.

Por fim, queremos ressaltar o importante papel que pode ser assumido pela Psicologia Social, qual seja: criar condições, por meio de suas práticas e dos conhecimentos produzidos, para que linhas de fuga sejam traçadas. Assim, ao contrário de indicar um rol de questões e/ou uma metodologia a ser replicada, objetivamos defender algo da ordem de uma sensibilidade: a problematização do modo de ser posto hoje, em que consumir(-se) fixa-nos, para alçar aberturas de vidas outras. Trabalho que pode acontecer em escolas, mas também em empresas, ONGs, associações etc., pois a questão do consumo transversaliza nossa vida. Neste sentido, atravessa os fazeres de psicólogos nos mais diversos campos de atuação, requerendo abordagens singulares, a serem inventadas.

Uma nota de encerramento: apesar de sua centralidade, pesquisas sobre consumo são bastante pontuais, especialmente aquelas que focalizam as vivências dos jovens. Ressaltamos, assim, a necessidade de que mais estudos venham a ser desenvolvidos - com diferentes enfoques, com a participação de outros atores sociais -, de modo a fazer frente à sua magnitude e complexidade.

\section{Referências}

Afonso, M. L. M., \& Abade, F. L. (2008). Para reinventar as rodas. Belo Horizonte, MG: Rede de Cidadania Mateus Afonso Medeiros.

Aguiar, K. F., \& Rocha, M. L. (2007). Micropolítica e o exercício da pesquisa-intervenção: referenciais e dispositivos em análise. Psicologia, Ciência e Profissão, 27(4), 648-663. https://doi.org/10.1590/S1414-98932007000400007

Arendt, H. (2010). A condição humana. Rio de Janeiro, RJ: Forense Universitária.

Barbosa, L., \& Campbell, C. (2006). O estudo do consumo nas ciências sociais contemporâneas. In L. Barbosa, \& C. Campbel (Orgs.), Cultura, consumo e identidade (pp. 21-44). Rio de Janeiro, RJ: Editora FGV.

Baudrillard, J. (2010). A sociedade de consumo. Lisboa: Portugal: Edições 70.

Bauman, Z. (1999). Globalização: as conseqüências humanas. Rio de Janeiro, RJ: Jorge Zahar.

Bauman, Z. (2008). Vidas para consumo: a transformação das pessoas em mercadorias. Rio de Janeiro, RJ: Jorge Zahar.

Bauman, Z. (2010). Vidas a crédito. Rio de Janeiro, RJ: Jorge Zahar.

Bragaglia, A. P. (2010). Comportamentos de consumo na contemporaneidade. Comunicação, Mídia e Consumo, 7(19), 107-124.

Brasil (2016, 25 de agosto). Quem somos e o que fazemos. Recuperado de http://www.vidaedinheiro.gov.br/pagina-29-quem_somos_e_o_que_fazemos.html

Calligaris, C. (2008). Privilegiados sem-vergonha. In C. Calligaris (Org.), Quinta coluna (pp. 187-190). São Paulo, SP: Publifolha.

Canclini, N. G. (2009). Consumo, acesso e sociabilidade. Comunicação, Mídia e Consumo, 6(16), 111-127. https://doi.org/10.18568/cmc.v6il6.159

Castro, L. R. (2008). Conhecer, transformar(-se) e aprender: pesquisando com crianças e jovens. In L. R. Castro \&V. L. Besset (Orgs.), Pesquisa-intervenção na infância e juventude (pp. 21-42). Rio de Janeiro, RJ: Nau.

Chesnais, F. (1995). A globalização e o curso do capitalismo de fim-de-século. Economia e Sociedade, 4(2), 1-30.

Coimbra, C., Bocco, F. \& Nascimento, M. L. do. (2005). Subvertendo o conceito de adolescência. Arquivos Brasileiros de Psicologia, 57(1), 2-11.

Costa, J. F. (2004). Perspectivas da juventude na sociedade de mercado. In R. Novaes, \& P. Vanuchi (Orgs.), Juventude e sociedade: trabalho, educação, cultura e participação (pp. 75-88). São Paulo, SP: Perseu Abramo. 
Debert, G. G. (2010). A dissolução da vida adulta e a juventude como valor. Horizontes Antropológicos, 16(34), 49-70. https://doi.org/10.1590/S0104-71832010000200003

Deleuze, G. (2008). Conversações, 1972-1990. São Paulo, SP: Ed. 34.

Deleuze, G., \& Guattari, F. (2007). Mil platôs: capitalismo e esquizofrenia (Vol. 1). São Paulo, SP: Ed. 34.

Fischer, R. M. B. (2001). Foucault e a análise do discurso em educação. Cadernos de Pesquisa, (114), 197-223. https://doi.org/10.1590/S0100-15742001000300009

Fontenelle, I. A. (2014). O estatuto do consumo na compreensão da lógica e das mutações do capitalismo. Lua Nova, (92), 207-240. https://doi.org/10.1590/S0102-64452014000200008

Foucault, M. (2014). A arqueologia do saber. Rio de Janeiro, RJ: Forense Universitária.

Foucault, M. (2000). A ordem do discurso. São Paulo, SP: Loyola.

Foucault, M. (1999). História da sexualidade: a vontade de saber. Rio de Janeiro, RJ: Edições Graal.

Foucault, M. (2008). Nascimento da biopolítica. São Paulo, SP: Martins Fontes.

Guattari, F. (2008). Caosmose: um novo paradigma estético. São Paulo, SP: Ed. 34.

Guttmann, R. (2008). Uma introdução ao capitalismo dirigido pelas finanças. Novos Estudos - CEBRAP, 82, 11-33. https:// doi.org/10.1590/S0101-33002008000300001

Hemais, M. W., Casotti, L. M., \& Rocha, E. P. G. (2013). Hedonismo e moralismo: consumo na base da pirâmide. Revista de Administração de Empresas, 53(2), 199-207. https://doi.org/10.1590/S0034-75902013000200007

Hennigen, I., \& Borges, J. P. (2014). Estigma moral e sofrimento psi: problematizando a individualização do superendividamento do consumidor. Estudos e Pesquisa em Psicologia, 14(1), 214-238.

Kehl, M. R. (2004). A juventude como sintoma da cultura. In R. Novaes, \& P. Vanuchi (Orgs), Juventude e sociedade: trabalho, educação, cultura e participação (pp. 89-114). São Paulo, SP: Perseu Abramo.

Lazzarato, M. (2006). As revoluções do capitalismo. Rio de Janeiro, RJ: Civilização Brasileira.

Lazzarato, M. (2012). The making of the indebted man. Los Angeles, CA: Semiotext(e).

Mattos, A. R., \& Castro, L. R. (2008). Ser livre para consumir ou consumir para ser livre? Psicologia em Revista, 14(1), 151-170.

Maurício de Souza Produções. (2009). Turma da Mônica em superendividados... até a raiz do cabelo. São Paulo, SP: Atlas.

Pereira, A. B. (2014). Funk ostentação em São Paulo: imaginação, consumo e novas tecnologias da informação e da comunicação. Revista de Estudos Culturais, 1, 1-18.

Rocha, A. P. R., \& Garcia, C. A. (2008). A adolescência como ideal cultural contemporâneo. Psicologia: Ciência e Profissão, 28(3), 622-631. https://doi.org/10.1590/S1414-98932008000300014

Rocha, M. L., \& Aguiar, K. F. (2003). Pesquisa-intervenção e a produção de novas análises. Psicologia, Ciência e Profissão, 23(4), 64-73. https://doi.org/10.1590/S1414-98932003000400010

Rocha, S. (2005). O homem sem qualidades: moderninade, consumo e identidade cultural. Comunicação, Mídia e Consumo, 2(3), 111-122. https://doi.org/10.18568/cmc.v2i3.28

Saraiva, K., \& Veiga-Neto, A. (2009). Modernidade líquida, capitalismo cognitivo e educação contemporânea. Educação \& Realidade, 34(2), 187-201.

Schwertner, S. F., \& Fischer, R. M. B. (2012). Juventudes, conectividades múltiplas e novas temporalidades. Educação em Revista, 28(1), 395-420. https:// doi.org/10.1590/S0102-46982012000100017

Severiano, M. F. V. (2006). Pseudo-individuação e homogeneização na cultura do consumo: reflexões críticas sobre as subjetividades contemporâneas na publicidade. Estudos e Pesquisas em Psicologia, 6(2), 105-121.

Silva, R. N. (2003). Ética e paradigmas: desafios da psicologia social contemporânea. In K. Ploner, L. R. F. Michels, L. M. Schilindwein, \& P. A. Guareschi (Orgs.), Ética e paradigmas na psicologia social (pp. 39-45). Porto Alegre, RS: Abrapso-SUL.

The Bubble Project. (2016). The bubble project. Recuperado de http://www.thebubbleproject.com/ 
Veblen, T. B. (1983). A teoria da classe ociosa: um estudo econômico das instituições. São Paulo: Abril Cultural. [Trabalho original publicado em 1899].

Weber, M. (1983). A ética protestante e o espírito do capitalismo. São Paulo, SP: Pioneira Editora.

\section{Inês Hennigen}

Psicóloga, Doutora em Psicologia pela PUC-RS, Professora do Departamento de Psicologia Social e Institucional do Instituto de Psicologia da UFRGS e docente do PPG em Psicologia Social e Institucional da UFRGS. E-mail: ineshennigen@gmail.com

\section{Bruno Eduardo Procopiuk Walter}

Psicólogo Organizacional na Universidade Tecnológica Federal do Paraná (UTFPR), Doutorando do Programa de Pós-graduação em Psicologia Social e Institucional da Universidade Federal do Rio Grande do Sul (UFRGS). E-mail: bruno.psi.utfpr@gmail.com

\section{Guilherme Machado Paim}

Graduando do Curso de Psicologia da Universidade Federal do Rio Grande do Sul (UFRGS).E-mail: guilhermepaim@ hotmail.com

Endereço para envio de correspondência:

Instituto de Psicologia da UFRGS; Rua Ramiro Barcelos, 2600, sala 311; CEP: 90035-003, Porto Alegre/RS

Recebido 08/09/2016

Aprovado 02/08/2017

Received 09/08/2016

Approved 08/02/2017

Recebido 08/09/2016

Aceptado 02/08/2017

Como citar: Hennigen, I., Walter, B. E. P., \& Paim, G. M. (2017). Consumo, dinheiro e diferenciações sociais: ditos de jovens em uma pesquisa-intervenção. Psicologia: Ciência e Profissão, 37(3), 711-724. https://doi.org/10.1590/1982-3703003412016

How to cite: Hennigen, I., Walter, B. E. P., \& Paim, G. M. (2017). Consumption, money and social differentiation: what was said by youngsters in an intervention research. Psicologia: Ciência e Profissão, 37(3), 711-724.

https://doi.org/10.1590/1982-3703003412016

Cómo citar: Hennigen, I., Walter, B. E. P., \& Paim, G. M. (2017). Consumo, dinero y diferenciaciones sociales: dichos de jóvenes en una investigación intervención. Psicologia: Ciência e Profissão, 37(3), 711-724. https://doi.org/10.1590/1982-3703003412016 